Bill spent the first years of his professional life in general practice in Belfast and Liverpool. He then moved to Claremont Street Hospital for Nervous Diseases, Belfast. There he worked under the distinguished neurologist R. S. Allison. In 1950 he decided to begin a career in psychiatry. He obtained a Fellowship at the Crichton Royal, Dumfries, Scotland, one of the foremost psychiatric hospitals in the UK. He was a student of Willi Mayer-Gross and R. Klein, both of whom were international authorities on neuropsychiatry. After some years he was appointed Consultant Psychiatrist at the Crichton Royal Hospital. While there he published several papers on involutional depression and electroencephalography with W. McAdam and A. Tait. In 1959 Bill McClatchey was appointed Deputy Physician Superintendent at Glasgow Royal Mental Hospital (now Gartnavel Royal Hospital). Six years later he moved to Perth, Scotland as Physician Superintendent of Murray Royal Hospital.

His practice of psychiatry was much influenced by his early experiences in general practice, by his keen interest in psychotherapy and by the application of psychoanalytical ideas in clinical work. Last, and by no means least, his practice was informed by a sensitivity for human beings and their frailties.

In his student days Bill was an outstanding athlete. As a swimmer, he represented his university and was a member of the Irish Water Polo team. Friendly by nature, he was always popular with fellow students and later with colleagues. He was a physically active man, swimming regularly until a few days before his death. He especially enjoyed playing the piano and listening to music - jazz or classical. In his retirement he travelled extensively. His wife, Jane, died in 1983. He leaves two sons - John, a Professor of Climatology and Alan, a general practitioner.

Thomas Freeman

\section{Mary D. S. Ainsworth}

Formerly Emeritus Professor, University of Vırginia, USA

Mary D. Salter Ainsworth, one of the pre-eminent developmental psychologists of the 20th century, died in Charlottesville, Virginia, on 21 March 1999, after a lengthy illness. She leaves behind an international family of students and friends. Her contributions to the scientific study of attachment led to groundbreaking changes in how we think about the bond between an infant and its care givers.

"Mary Ainsworth stands out as one of the major figures of the twentieth century in the study of the relations between young children and their caregivers. Her work on the nature and development of human security, her exquisite naturalistic observations of attachment-care-giving interactions, her conceptual analyses of attachment, exploration and self-reliance, and her contributions to methodology of infant assessment are cornerstones of modern attachment theory and research. The patterns of attachment that she identified have proven robust in research across diverse cultures and across the human lifespan. Her contributions to developmental psychology, developmental psychopathology, and ultimately to clinical psychology, as well as her teaching, colleagueship, and grace, are the secure base from which future generations of students can explore." (Citation for Mary D. Ainsworth, on the occasion of receiving The Gold Medal Award for LifeAchievement in the Science of Psychology, American Psychological Foundation, 1998) Professor Ainsworth was born in Glendale, Ohio in 1913, the daughter of Charles and Mary Salter. She spent most of her childhood in Toronto, Canada. She earned her BA from the University of Toronto in 1935, her MA in 1936, and her PhD in developmental psychology in 1939. She then held a position as lecturer in the Psychology Department until 1942, when she was commissioned in the Canadian Women's Army Corps, attaining the rank of Major. She returned to the University

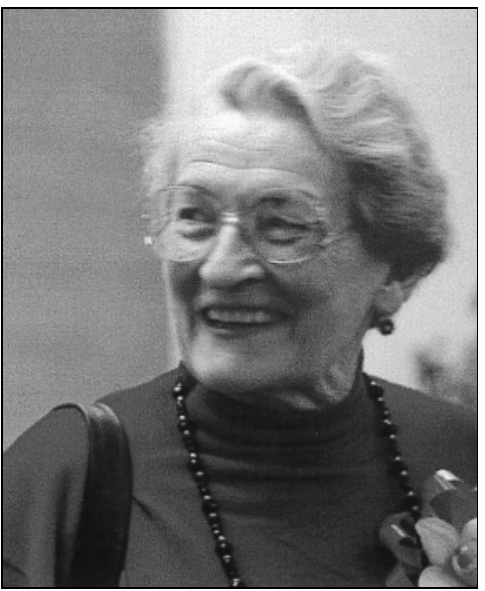

of Toronto as Assistant Professor in 1946 where she wrote an influential collaborative book with Klopfer on the Rorschach Test.

In 1950, Mary Salter married Leonard Ainsworth, a Second World War veteran and graduate student in psychology, and moved to London, England. There she began a life-long collaborative partnership with John Bowlby, a child psychiatrist who was investigating the devastating effects that prolonged separation from the mother in early childhood had on young children in hospitals and institutions. From London she moved to Kampala, Uganda where she conducted one of the first longitudinal, scientific studies of motherinfant interaction in the first year of life.

In 1955, Professor Ainsworth moved

to Baltimore, Maryland where she conducted clinical work and joined the faculty of the Johns Hopkins University. She was appointed Associate Professor in 1958 and Full Professor in 1963. In 1962, she began her renowned Baltimore study of infant-care-giver attachment. This study led to major changes in how parents, psychologists, psychiatrists, paediatricians, educators and policy-makers worldwide think about parenting infants and very young children.

In 1974, Mary Ainsworth moved to the University of Virginia, first as Visiting Professor, then as Commonwealth Professor from 1975-1984. During this time she continued teaching developmental psychology, supervising the research of many graduate students, and publishing the results of her own research. She also played a key role in the development of the clinical psychology training programme at the University of Virginia. She retired as Professor Emeritus in 1984, after which she remained professionally active until 1992

In her life time Professor Ainsworth was honoured by many prestigious organisations, including the Honorary Fellowship of the Royal College of Psychiatrists. She was the author of innumerable publications, including the renowned Child Care and the Growth of Love, written with John Bowlby which had its second publication in 1965.

\section{Reference}

BOWLBY, J. \& AINSWORTH, M. D. S. (1965) Child Care and Growth of Love (2nd edn). London: Penguin.

\section{Bob Marvin}

